\title{
Potassium fertilisation and the thermal behaviour of Cynara cardunculus L.
}

\author{
M.L. Solano , E. Manzanedo , R. Concheso , M.D. Curt , M. Sanz , J. Fernández \\ Departamento de Energías Renovables, CIEMAT, Avda. Complutense 22, 28040 Madrid, Spain \\ Departamento de Producción Vegetal: Botánica y Protección Vegetal, Escuela Técnica Superior de Ingenieros Agrónomos, \\ Universidad Politécnica de Madrid (UPM), 28040 Madrid, Spain
}

Keywords:

Cynara biomass

Potassium fertilisers

Combustion

Thermal Analysis

Scanning electron microscopy

\begin{abstract}
A B S T R A C T
Herbaceous biomass like Cynara is commonly high in potassium, chlorine and ash, which has been reported as a source of problems for combustion applications. An appropriate management of the potassium fertilisation is suggested as a way of improving the quality of the Cynara biomass for solid fuel applications. In this work a factorial experiment was designed involving two types of fertilisers, $\mathrm{KCl}$ and $\mathrm{K}_{2} \mathrm{SO}_{4}$, and two $\mathrm{K}$ rates, in order to study the effect of potassium fertilisation on the composition and thermal behaviour of Cynara biomass.

The results proved that the potassium content of Cynara biomass increases with the potassium fertilisation. The thermogravimetric study showed that sintering phenomena can be expected at temperatures higher than $900^{\circ} \mathrm{C}$ when the crop has been highly $\mathrm{K}$-fertilised, irrespective of the type of fertiliser used, $\mathrm{KCl}$ or $\mathrm{K}_{2} \mathrm{SO}_{4}$. However, the SEM images taken of samples of the four $\mathrm{K}$ treatments of this experiment did not reveal signs of ash melting, although some particles with crystalline appearance appeared in the samples from highly $\mathrm{K}$-fertilised treatments.
\end{abstract}

\section{Introduction}

Modem society has created unprecedented demands for energy based on fossil sources. However, there is a growing consensus about the diminishing supply of petroleum sources and the negative environmental consequences of burning fossil fuels. Issues such as security of supply, climate change, employment, or rural development, have led to the need to move forward and to support and encourage the use of renewable energy sources. It is clear that biomass is currently gaining the attention of the European Institutions as part of a joint European effort in the promotion of these renewable energy sources. There is a need for integrated energy systems that can use different feedstocks (such as energy crops or biomass residues and wastes) and generate products such as fuel, heat and electricity. In this context, soljd biomass offers an economically attractive altemative to fossil fuels.

At this time, when bioenergy production is being suggested as one of the causes of the price increases for some agricultural commodities, it is necessary to find new crops for energy which are not in competition with those utilized for food or animal feed. Many countries around the World have been developing new crops since the mid 1970s in order to increase the biomass resource base for production of bioenergy. Since then, the technical feasibility of producing energy crops has progressed significantly and several bioenergy projects based on energy crops have been developed. 
Among the plant species studied as energy crops, Cynara cardunculus $\mathrm{l}$. can be considered as one of the crops with the most potential for biomass production in rajnfed lands with Mediterranean climates. As a matter of fact, the species, which is a perennial herb with an annual growth cycle, is native to the Mediterranean region, where it has been traditionally grown for horticultural purposes - particularly in Italy, France and Spain - since ancient times. In that context it is commonly known as "cardoon" but for energy purposes the species is grown as a field crop and then the name "Cynara" is normally used. The remarkable surge of interest in this crop in recent is due to its non-food utilization.

The Cynara energy crop has demonstrated its adaptation to the Mediterranean environment in various European $R+D$ projects. A review of it as an energy crop can be found in [1]. The research work done has shown the potential of this species for biomass production as well as the different applications of the crop produce: the lignocellulosic biomass as solid biofuel for heat or power generation and even as a substrate for paper pulping [2], and the seed oil for biodiesel. The energy and traditiona] applications of this crop are detajled in [3].

When it comes to the utilization of the biomass for heat or electricity, the lignocellulosic biomass of Cynara (heads containing oil seeds not included) seems to have similar characteristics to other herbaceous biomasses like straw; moisture content about $10-15 \%$ and low heating value (LHV) between 15 and $16 \mathrm{MJ} \mathrm{kg}^{-1}$. Recent articles have shown that the quality of the biomass harvested from this crop needs to be improved for its application as a solid biofuel [4].

Much concern has been expressed about some reported values of Cynara ash, potassium and chlorine content $(5-20 \%$, $2-2.5 \%$ and $0.3-1.7 \%$, respectively) and about the slagging problems at temperatures over $750^{\circ} \mathrm{C}$ experienced by some authors [5]. The high ash content of some samples has been attributed to soil contamination as a consequence of the harvesting method $[1,4]$ while slagging problems could be a consequence of the high contents of potassium and chlorine. High potassium contents have been related to mechanisms of osmotic adjustment in Cynara seedlings [6] However, little is known about the effect of the potassium fertilisation, $K$ rate and type of fertiliser on these contents. When a biomass is combusted in large-scale power plants, a low chlorine and potassium content is desirable, because the presence of these compounds reduces the capacity and efficiency of thermal conversion plants [7]. As a guide, contents of $<0.1 \%$ for $\mathrm{Cl}$ and $<7 \%$ for $\mathrm{K}$ are recommended for unproblematic thermal utilization of biomass fuels [8].

Nevertheless, in living plants, large quantities of alkali metals are required as nutrients and counter ions. Potassium is especially abundant in annual and short-life crops, with sodium also present in minor amounts. In the fast growing parts of trees (small branches and leaves), the alkali content is higher than in the trunk and larger branches. Around $90 \%$ of the alkali in biomass is present in water-soluble or ion exchangeable form and is susceptible to vaporization during heating [9]. In therma] conversion plants the release of alkali compounds causes the formation of molten salt mixtures on accessible surfaces like exposed boiler parts, fly ash particles and flujdized bed material. Silica sand is often used as bed material during fluidized bed combustion, and low-melting eutectic mixtures of alkali compounds and silica may be formed. A liquid layer on the bed material particles tends to induce agglomeration, which leads to impaired fluidization and mixing conditions. Fouling, the formation of ash deposits on surfaces like screen tubes and superheaters, is primarily associated with the presence of compounds containing potassium, chlorine, and silicon. of the various operational problems connected with fouling, the reduction in heat transfer rates and accelerated corrosion are often the most serious $[10,11]$.

Several methods of reducing the detrimental effects of the alkali compounds have been proposed. Recent studies have shown that additives such as kaolin or dolomite are capable of reducing sintering problems by raising the melting point of the ash. Alternatively the vaporization of alkali compounds may be reduced by a decrease in process temperature or a Cynara-coal co-firing. Another approach is to lower the content of alkali metals in the feedstock or to change the supply of nutrients. Potassium, the most abundant alkali in herbaceous biomass, is a macronutrient and, therefore, its supply should be optimized in order to meet the needs of the crop without permitting excess consumption. So, changes in fertilisation strategies are required in order to avoid the detrimental effects mentioned above when biomass, particularly Cynara, is utilized as an energy crop for heat or electricity production.

In addition to this, codes of good agricultural practice and environmental guidelines should be respected; otherwise growing energy crops on agricultural lands will create additional pressure on biodiversity, soil, and water resources. In biomass production, the most negative environmental effects are caused by the utilization of chemicals and fertilisers [12]. Thus, improvements are necessarily dependent on the optimisation of these elements.

Consequently, the aim of the current study was to investigate the effect of potassium fertilisation on the themal behaviour of Cynara. Since severa] authors $[13,14]$ have shown that chlorine facilitates alkali release and may, therefore, serve as a "potassium carrier" from the fuel to accessible surfaces; in this work two distinct potassium fertilisers $-\mathrm{KCl}$ and $\mathrm{K}_{2} \mathrm{SO}_{4}$ - were experimented on the Cynara energy crop, at two different rates. Thermal analysis of Cynara biomass and scanning electron microscopy (SEM) studies of the ash which had been obtained in the TGA/DTA analysis was carried out in each of the fertiliser treatments in order to evaluate the influence of the rate and type of fertiliser on the thermal behaviour of Cynara biomass.

\section{Materials and methods}

\subsection{Field experiment}

The field trials were carried out in the 2003-04 season in the Experimental Fields of the Agroenergy Group of the Polytechnic University of Madrid, Spain (latitude $40 \underline{0} 26^{\prime} 36^{\prime \prime} \mathrm{N}$, longitude $3 \underline{o} 44^{\prime} 18^{\prime \prime} \mathrm{W}$, altitude $595 \mathrm{~m}$ ). The expeniment design for the field trials was: 2 potassium rates $\times 2$ types of potassium fertilisers $\left(\mathrm{KCl}\right.$ and $\left.\mathrm{K}_{2} \mathrm{SO}_{4}\right) \times 3$ replications, plus the control (non-K-fertilised treatment). 
The experiment was performed in $40 \times 60 \times 40 \mathrm{~cm}$ containers, filled with a low-fertility soil in order to enhance the effect of the fertilisation. The soil characteristics were the following: sandy texture $(77.6 \%$ sand, $6.4 \%$ silt, $16 \%$ clay $), \mathrm{pH}$ ( $1: 2.5 \mathrm{H}_{2} \mathrm{O}$ ) 8.2 , organic matter $0.32 \%$, nitrogen $0.11 \% \mathrm{~N}$, phosphorous (Olsen) $19 \mathrm{ppm} \mathrm{P}$, potassium $\left(1 \mathrm{~mol} \mathrm{~L}^{-1}\right.$ ammonium acetate) $148 \mathrm{ppm} \mathrm{K}$, chlorine (2:10 soil/water) $135 \mathrm{ppm} \mathrm{Cl}$. One Cynara plant per container was used. The plants had been individually grown from seed for two months in $12 \mathrm{~cm}$ diameter pots filled with the soil previously described. All the plants came from a seed pool of Cynara for biomass production (Cynara ETSIA).

Fertilisation was performed following results of previous studies [15]. In this experiment, nitrogen and phosphorous nutrients were applied in all the tests equally, at the rate of $25.2 \mathrm{~g} \mathrm{~N}$ and $7 \mathrm{~g} \mathrm{P}_{2} \mathrm{O}_{5}$ per container. Two different rates of potassium were experimented: Rate 1 was equivalent to $20.8 \mathrm{~g}$ $\mathrm{K}$ and Rate 2, twice that quantity. Consequently the treatments applied in this experiment were labelled for short as: $0 \mathrm{~K}$ (control), $1 \mathrm{KCl}, 1 \mathrm{~K}_{2} \mathrm{SO}_{4}, 2 \mathrm{KC}$ ) and $2 \mathrm{~K}_{2} \mathrm{SO}_{4}$.

The crop was allowed to grow according to the natural growth cycle of the species. In August, once the cycle was completed and the aerial biomass was dry, the aboveground biomass was carefully cut off at a height of approximately $5 \mathrm{~cm}$ above the soil so that soil particles would not contaminate it. The plant biomass was fractionated by hand to determine the weight of the stalk, as well as the weight of the harvestable biomass (cauline leaves + stalk + capitula). Then, the stalk fraction was taken to conduct the analytical determinations.

\subsection{Analysis of the plant material}

The plant material was processed as received at the laboratory; no water washing was performed. First it was dried separately at $105^{\circ} \mathrm{C}$ unbl constant weight was achieved (ASTM D 2016-65 "moisture content of wood") and then it was ground into a fine powder (particle size $\leq 1 \mathrm{~mm}$ ).

The effect of the $\mathrm{K}$ fertilisation was studied for content in $\mathrm{C}$, $\mathrm{N}, \mathrm{P}, \mathrm{K}, \mathrm{Cl}, \mathrm{S}$ and ash. Biomass content in $\mathrm{C}, \mathrm{N}$ and $\mathrm{S}$ was determined by elemental analysis. Potassium content was determined by flame emission photometry on samples ashed at $450^{\circ} \mathrm{C}$ for $4 \mathrm{~h}$. Chlorine content was determined by Volhard's method according to the norm ASTM D-2361-66. Ash content was determined following UNE-CEN/TS14775:2004. All results were expressed as a percentage of dry weight. Statistical analysis was performed for each variable by means of one-way ANOVA in order to test the null hypothesis (no difference between treatments). Tukey's test was used to separate means whenever statistical significance was found $(p<0.05)$.

\subsection{Thermogravimetric analysis}

The sintering/melting behaviour of the Cynara biomass was studied using thermogravimetric measurements. Thermogravimetric analysis TG/DTA was attained using a SEIKO TG/ DTA 6300 instrument.

Cynara biomass samples were placed in a platinum sample pan and heated from room temperature to $1300^{\circ} \mathrm{C}$ at a $10^{\circ} \mathrm{C} \mathrm{min}^{-1}$ using a $50 \mathrm{ml} \mathrm{min}^{-1}$ flow of air. The performance of the system was regularly checked by measuring the three decomposition steps of calcium oxalate monohydrate.

The continuous on-line records of weight loss and temperature were obtained to plot the TG curve. Differential thermal analysis (DTA) is a technique that involves recording the difference in temperature between a substance and an inert reference material as the two specimens are subjected to identical temperature regimes in an environment heated at a controlled rate. The record obtained is called a DTA curve and, provided that the substance is thermally active in the temperature range used, shows a series of peaks. In this curve any physical or chemical process which involves an energy change (consumption or release), is represented as either endothermic or exothermic peaks. Therefore, this technique allows us to detect any sintering, melting or other phenomenon that could occur in the sample when it is heated from room temperature up to $1300^{\circ} \mathrm{C}$ with a constant heating rate.

\subsection{Scanning electron microscopy and energy dispersive $X$-ray analysis (SEM-EDX)}

Lumps of Cynara ash were collected from the thermogravimetric experiments after the end of each test and then examined using scanning electron microscopy (SEM). The SEM utilized was a Digital Scanning Microscope DSM 960 Zeiss which has micro-probe equipment, based on energy dispersive $\mathrm{X}$-ray fluorescence analysis giving the elemental composition at chosen points on the sample surface.

Some carbon paint was first applied to the sample holding discs. Each sample was then placed on the carbon paint to obtain good conductivity between the sample and the disc surface. All the samples were then coated with gold-palladium alloy in order to avoid charging and to obtain better images during the SEM analysis. The coated samples were placed into the SEM for image and energy dispersive $\mathrm{X}$-ray analysis. The acceleration voltage was set to the level of $20 \mathrm{kV}$ and the back-scattered electron image was used for the whole analysis. Magnifications in the range of $100-2000 \times$ were selected, depending on the visual field that needed to be examined. To obtain a good quality image, the contrast level that discriminates between the background and the sample was also adjusted and the SEM picture was then taken.

\section{Results}

\subsection{Analysis of plant material}

Mean results of the biomass production and the analysis of plant material, and the statistical significance between the treatments tested, are shown in Table 1 . The values obtained for $\mathrm{N}, \mathrm{K}, \mathrm{Cl}, \mathrm{S}$ and ash were more adequate for solid biofuel applications than the values reported in the literature $[4,16]$. This fact can be attributed to the harvesting process, because the mechanical harvesting of Cynara with conventional machinery has until now always implied soil contamination. That problem was also stressed by other authors [4]. The biomass in this experiment, however, was harvested by hand. 
Table 1 - Mean results of the Cynara experiment and analysis of the variance (ANOVA). BDW = biomass dry weight (cauline leaves + stalk + capitula) at the end of the growth cycle; C, N, P, K, Cl, S, and ash = carbon, nitrogen, phosphorous, potassium, chlorine, sulphur and ash content (weight $\%$ d.b.).

\begin{tabular}{lcl} 
Parameter & Mean & ANOVA \\
\hline BDW (g) & 178.5 & $\mathrm{~ns}$ \\
Stalk proportion (\%) & 39.2 & $\mathrm{~ns}$ \\
C (\%) & 38.9 & $\mathrm{~ns}$ \\
$\mathrm{~N}(\%)$ & 0.50 & $\mathrm{~ns}$ \\
P (\%) & 0.18 & $\mathrm{~ns}$ \\
K (\%) & 1.18 & $p=0.0114$ \\
Cl (\%) & 0.31 & $\mathrm{~ns}$ \\
S (\%) & 0.11 & $p=0.0003$ \\
Ash (\%) & 6.87 & $\mathrm{~ns}$ \\
\hline
\end{tabular}

ns: no significant differences.

Even so, our Cynara plant material contained more N, P, K, S, $\mathrm{Cl}$ and ash than woody solid biofuels [17].

The results in Table 1 show the effect of the $\mathrm{K}$ fertiliser on the quality of the biomass. Significant differences were found for the biomass content in $\mathrm{K}$ and $\mathrm{S}$. No statistical significance was found, however, for the chlorine content.

In Table 2 the average values of $\mathrm{K}, \mathrm{S}$ and ash content obtained for each fertiliser treatment are given. The ash values were within the range of other herbaceous materials like straw; they were in the range of $6.3-6.8 \%$ for all the treatments except for the $2 \mathrm{~K}_{2} \mathrm{SO}_{4}$ treatment. As with [18], $\mathrm{K}$ fertilisation resulted in an increase of the stalk $\mathrm{K}$ content in comparison to the control (non-K-fertilised treatment), which could be related to the type of fertiliser. With the same type of fertiliser, Rate 2 resulted in higher values than Rate 1; however, no statistical differences were found either for the $\mathrm{KCl}$ trials or for the $\mathrm{K}_{2} \mathrm{SO}_{4}$ ones. For the purpose of solid biofuel, the values found for the $\mathrm{K}$ content of the different treatments are considered high, although they are lower than the values reported by different authors $[4,16]$; these values suggest that sintering problems could arise in the course of the biomass combustion.

As regards sulphur, all the $\mathrm{K}$-fertilised treatments resulted in higher S stalk contents versus the control; this could be attributed to an effect of the balance between the different macronutrients. The value obtained for Rate 2 of $\mathrm{K}_{2} \mathrm{SO}_{4}$ fertiliser was statistically different to the other $\mathrm{K}$-fertilised

Table 2 - Mean results (weight $\%$ d.b.) of the Cynara biomass content in potassium, sulphur, chlorine and ash obtained for each fertilisation trial. In each column the values followed by the same letter are not statistically different according to Tukey's test.

\begin{tabular}{lllcc} 
Treatment & $\mathrm{K}(\%)$ & $\mathrm{S}(\%)$ & $\mathrm{Cl}(\%)$ & Ash (\%) \\
\hline Control & $0.66 \mathrm{~b}$ & $0.06 \mathrm{c}$ & 0.17 & 6.38 \\
$1 \mathrm{KCl}$ & $1.13 \mathrm{ab}$ & $0.12 \mathrm{~b}$ & 0.22 & 6.77 \\
$1 \mathrm{~K}_{2} \mathrm{SO}_{4}$ & $1.33 \mathrm{a}$ & $0.12 \mathrm{~b}$ & 0.35 & 6.26 \\
$2 \mathrm{KCl}^{\mathrm{K}}$ & $1.20 \mathrm{ab}$ & $0.11 \mathrm{~b}$ & 0.60 & 6.41 \\
$2 \mathrm{~K}_{2} \mathrm{SO}_{4}$ & $1.57 \mathrm{a}$ & $0.16 \mathrm{a}$ & 0.21 & 8.53 \\
\hline
\end{tabular}

treatments but there were no significant differences between Rate 1 of that fertiliser and the $\mathrm{KCl}$ trials. This fact suggests that the use of $\mathrm{K}_{2} \mathrm{SO}_{4}$ at Rate 1 instead of $\mathrm{KCl}$ would not result in a lower quality biomass, from the point of view of the sulphur. With regard to the chlorine a high level of variation was observed within each treatment. Hence, no significant differences were obtained between treatments in spite of the fact that the $\mathrm{KCl}$ fertiliser applied at Rate 2 resulted in higher chlorine contents.

\subsection{Scanning electron microscopy and energy dispersive $\mathrm{X}$-ray (SEM-EDX) and DTA analysis}

Fig. 1(a) depicts the morphology of the ash particles of the control sample that appear to be rough and irregular. As can be seen from Table 3 , the ash particles contain mainly calcium. This element may be in the form of calcium carbonate since in Fig. 1(b) the DTA curve shows two endothermic peaks in the temperature interval $639^{\circ} \mathrm{C}-874^{\circ} \mathrm{C}$. This endothermic reaction is associated with a weight loss starting already at lower temperatures. The weight loss at $570^{\circ} \mathrm{C}$ is attributed to the decomposition of $\mathrm{Ca}(\mathrm{OH})_{2}$, which is supported by the characteristic DTA peak. The presence of $\mathrm{CaCO}_{3}$ is proved by the DTA peak at $874{ }^{\circ} \mathrm{C}$ and the release of $\mathrm{CO}_{2}$ at the same temperature [19]. This leads us to the conclusion that the main reaction causing these effects is the $\mathrm{CO}_{2}$

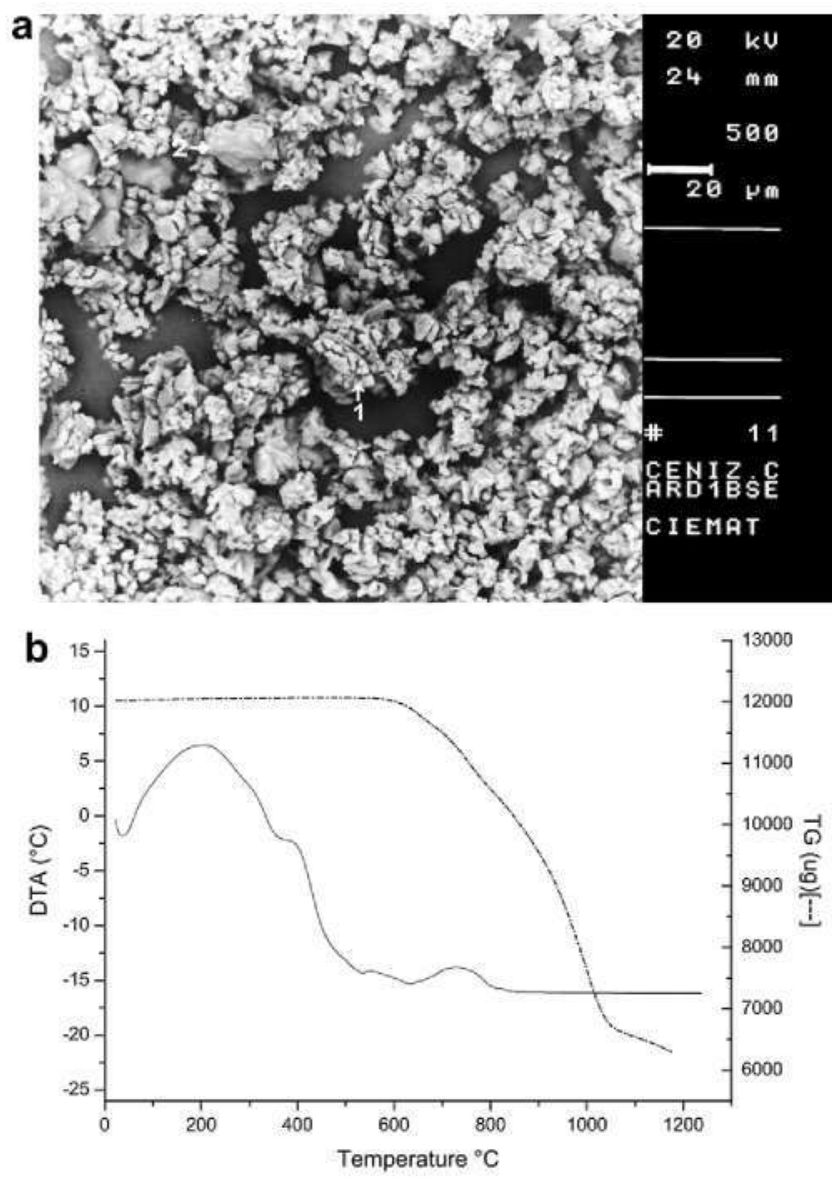

Fig. 1 - Non-K-fertilised treatment (Control): (a) SEM-EDX photo of particles (Point 1 and Point 2), and (b) DTA curve. 
Table 3 - SEM-EDX analysis of particles (P1 and P2) found in the non- $\mathrm{K}$-fertilised treatment (Control).

\begin{tabular}{lcc}
$\begin{array}{l}\text { Sample composition } \\
(\%)\end{array}$ & $\mathrm{P} 1$ & $\mathrm{P} 2$ \\
\hline $\mathrm{SiO}_{2}$ & 0.6 & 3.2 \\
$\mathrm{Al}_{2} \mathrm{O}_{3}$ & ip & 0.9 \\
$\mathrm{~K}_{2} \mathrm{O}$ & 5.9 & 2.2 \\
$\mathrm{Na}_{2} \mathrm{O}$ & ip & 13.6 \\
$\mathrm{CaO}$ & 87.9 & 40.6 \\
$\mathrm{MgO}$ & 5.3 & ip \\
$\mathrm{P}_{2} \mathrm{O}_{5}$ & ip & 39.1 \\
ip $=$ imperceptible. & &
\end{tabular}

evolution from carbonates, above all $\mathrm{CaCO}_{3}$, a conclusion which is in agreement with [20].

In the case of Treatment $1 \mathrm{KCl}$, the SEM picture shows that the particles are very similar to those observed in the control, both in morphology and composition, as can be seen in Fig. 2 and Table 4, respectively.

However, in Treatment $2 \mathrm{KCl}$, among a mass of amorphous particles with high calcium content, some particles with crystalline appearance also appeared. As can be seen in

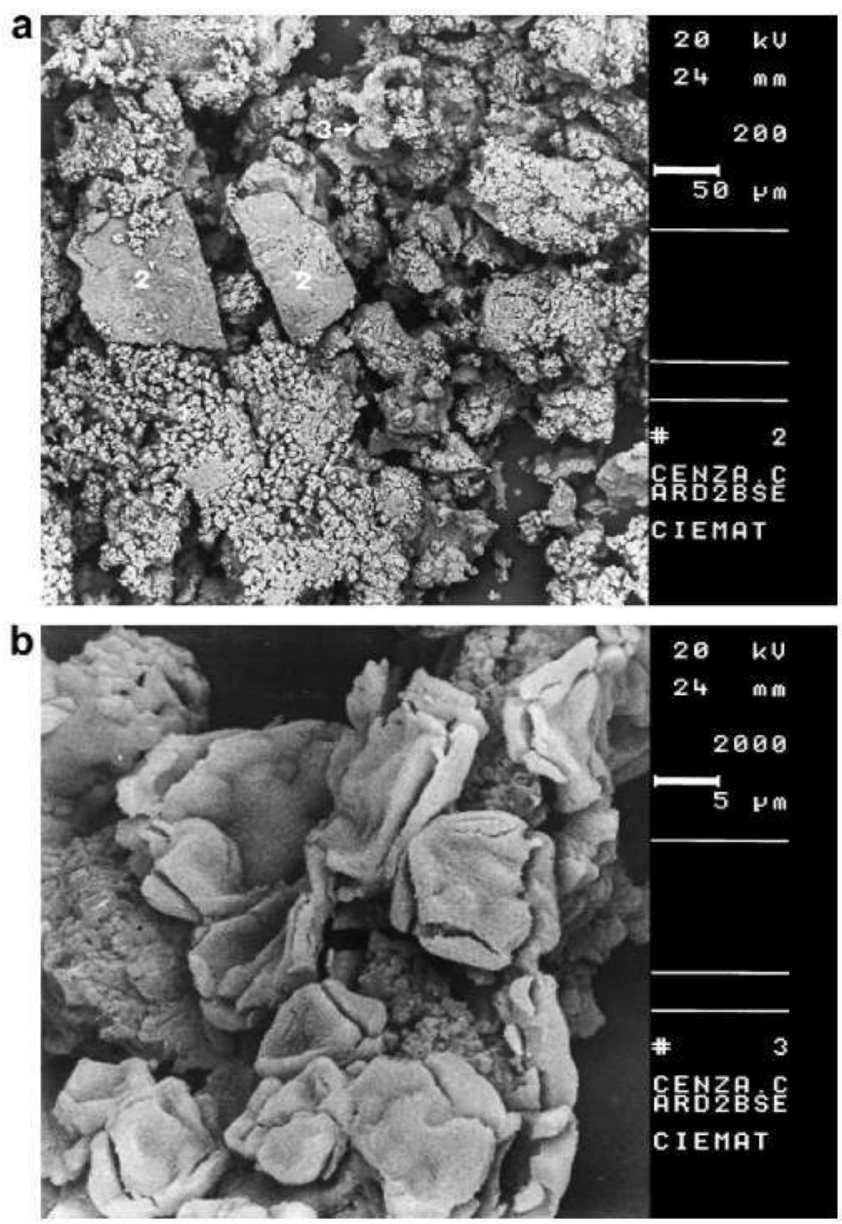

Fig. 2 - SEM-EDX photo of particles found in the sample corresponding to Treatment 1KCl: (a) Point 2 and Point 3 , and (b) detail of Point 3.
Table 4 - SEM-EDX analysis of particles (P2 and P3) found in the sample corresponding to Treatment $1 \mathrm{KCl}$.

\begin{tabular}{lcc}
$\begin{array}{l}\text { Sample composition } \\
(\%)\end{array}$ & P2 & P3 \\
\hline $\mathrm{SiO}_{2}$ & 1.6 & 1.3 \\
$\mathrm{Al}_{2} \mathrm{O}_{3}$ & ip & ip \\
$\mathrm{K}_{2} \mathrm{O}$ & 4.1 & 8.0 \\
$\mathrm{Na}_{2} \mathrm{O}$ & 1.3 & 1.4 \\
$\mathrm{CaO}$ & 88.1 & 83.2 \\
$\mathrm{MgO}$ & 4.8 & 6.0 \\
$\mathrm{P}_{2} \mathrm{O}_{5}$ & ip & ip \\
ip $=$ imperceptible. & &
\end{tabular}

Table 5, the composition of these particles was dominated by silicon, potassium and aluminium, in much the same way as has been observed in other biomass (rape, wheat or barley straw). These findings are in agreement with those reported by other authors [21] who showed that the ash from rape straw was mainly crystalline with a relatively high ash melting point, whereas the ash produced from wheat and barley contained significant amounts of amorphous material Fig. 3.

In contrast, the thermogravimetric study shows different sample behaviour depending on the $\mathrm{KCl}$ rate. As can be observed in Fig. 4, when the $1 \mathrm{KCl}$ treatment was applied, only the peak corresponding to the $\mathrm{CO}_{2}$ release was observed. However, when the $2 \mathrm{KCl}$ treatment was utilized, two endothermic peaks appeared at high temperatures $\left(947^{\circ} \mathrm{C}\right.$ and $1094^{\circ} \mathrm{C}$ ). Given the chemical composition of the particles with crystalline appearance observed in this sample (Table 5), these peaks could be due to the formation of low melting eutectics between the silica and potassium compounds. This is in agreement with [10], who have reported that at higher temperatures part of the silica in the ash material forms calcium silicates by a reaction with calcium oxide, and also concurs with [22] who have shown that alkalis and alkali earth metals tend to react with silicon in the form of silica $\left(\mathrm{SiO}_{2}\right)$, and create low melting point silicates.

Concerning the samples fertilised with $\mathrm{K}_{2} \mathrm{SO}_{4}$, some hard, brittle particles appeared in those fertilised at Rate 1 (Treatment $1 \mathrm{~K}_{2} \mathrm{SO}_{4}$ ) (see Fig. 5), with potassium as the main compound $(92.8 \%)$, and lower amounts of sodium (7.1\%).

Table 5 - SEM-EDX analysis of particles with crystalline appearance (P1 and P2) and amorphous particles (P3) found in the sample corresponding to Treatment $2 \mathrm{KCl}$.

\begin{tabular}{lrcc}
$\begin{array}{l}\text { Sample composition } \\
(\%)\end{array}$ & $\mathrm{P} 1$ & $\mathrm{P} 2$ & $\mathrm{P} 3$ \\
\hline $\mathrm{SiO}_{2}$ & 43.8 & 40.2 & 1.1 \\
$\mathrm{Al}_{2} \mathrm{O}_{3}$ & 9.8 & 27.7 & ip \\
$\mathrm{K}_{2} \mathrm{O}$ & 24.9 & 31.1 & 11.4 \\
$\mathrm{Na}_{2} \mathrm{O}$ & 3.7 & 0.9 & 1.4 \\
$\mathrm{CaO}$ & 9.5 & ip & 79.1 \\
$\mathrm{MgO}$ & 6.8 & ip & 7.0 \\
$\mathrm{P}_{2} \mathrm{O}_{5}$ & ip & ip & ip \\
ip =imperceptible. & & &
\end{tabular}




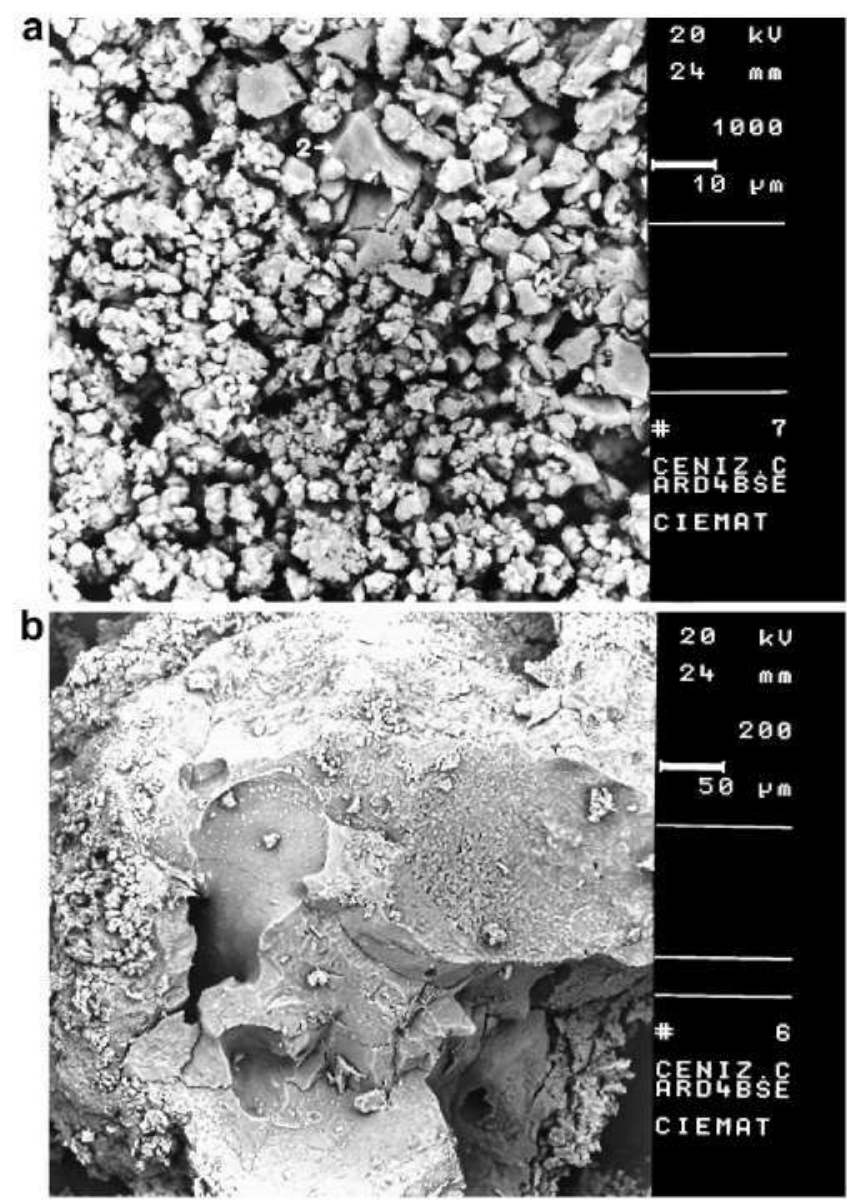

Fig. 3 - SEM-EDX photo of particles from the sample corresponding to Treatment $2 \mathrm{KCl}$.

As with the particles present in the ash of samples corresponding to Treatment $1 \mathrm{KCl}$ and according to the DTA curve (see Fig. 6) which showed a peak at around $880^{\circ} \mathrm{C}$, these ash particles are probably carbonates, since at that temperature $\mathrm{CO}_{2}$ release occurs. Nevertheless, as also can be seen in Fig. 6 ,

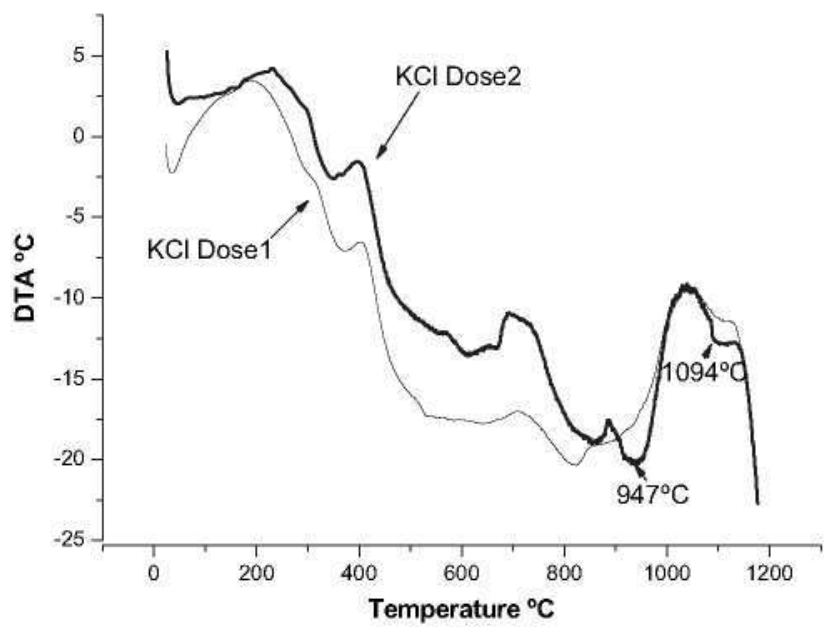

Fig. 4 - DTA curves of the samples from Treatments $1 \mathrm{KCl}$ and $2 \mathrm{KCl}$.

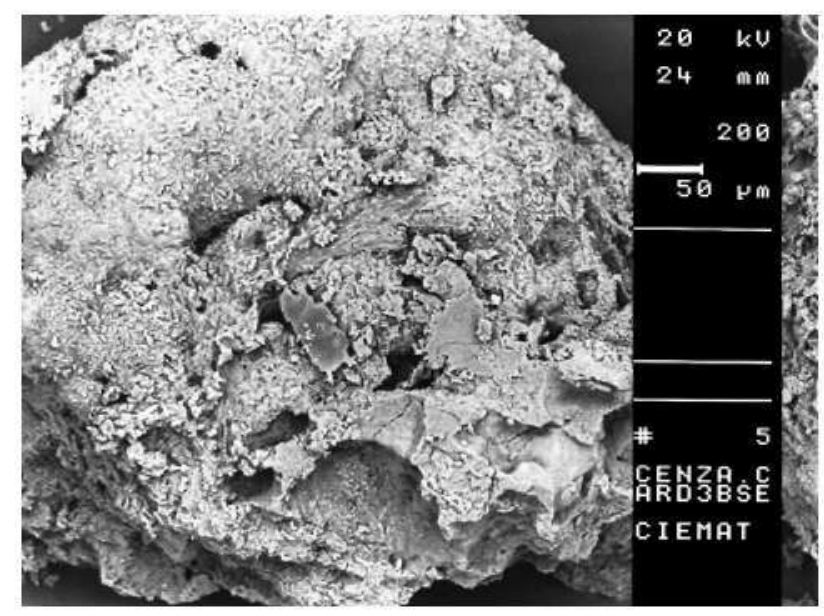

Fig. 5 - SEM-EDX photo of a particle found in the sample corresponding to Treatment $1 \mathrm{~K}_{2} \mathrm{SO}_{4}$.

the DTA curve of the sample corresponding to Treatment $1 \mathrm{~K}_{2} \mathrm{SO}_{4}$ presented a clear endothermic peak at $1086^{\circ} \mathrm{C}$. This might be due to a melting of crystalline particles; however, this kind of particles does not appear in the SEM-EDX analysis.

Finally, the SEM-EDX analysis of the samples corresponding to Treatment $2 \mathrm{~K}_{2} \mathrm{SO}_{4}$ showed two different kinds of particles (Fig. 7), some isolated hard particles with a crystalline appearance which presented higher potassium contents and others with an amorphous aspect and a very high calcium content (Table 6).

As can be observed in Fig. 6, the DTA curve of these samples showed two endothermic peaks around $812^{\circ} \mathrm{C}$ and $900^{\circ} \mathrm{C}$, the first one probably due to the $\mathrm{CO}_{2}$ release as a consequence of the decomposition of the calcium carbonates present in the amorphous particles. Besides, from $1000^{\circ} \mathrm{C}$ upwards a sharp fall occurred, in a similar way to the sample corresponding to Treatment $2 \mathrm{KCl}$. This fall could be indicating the beginning of a great endothermic peak which was impossible to detect, due to the technical limits of the TG/DTA utilized, and could represent the melting of particles with

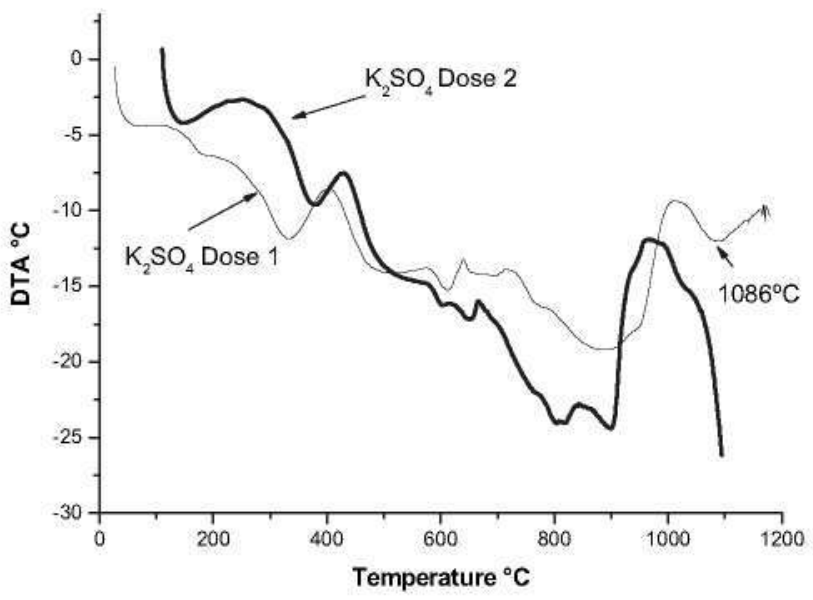

Fig. 6 - DTA curves of the samples from Treatments $1 \mathrm{~K}_{2} \mathrm{SO}_{4}$ and $2 \mathrm{~K}_{2} \mathrm{SO}_{4}$. 


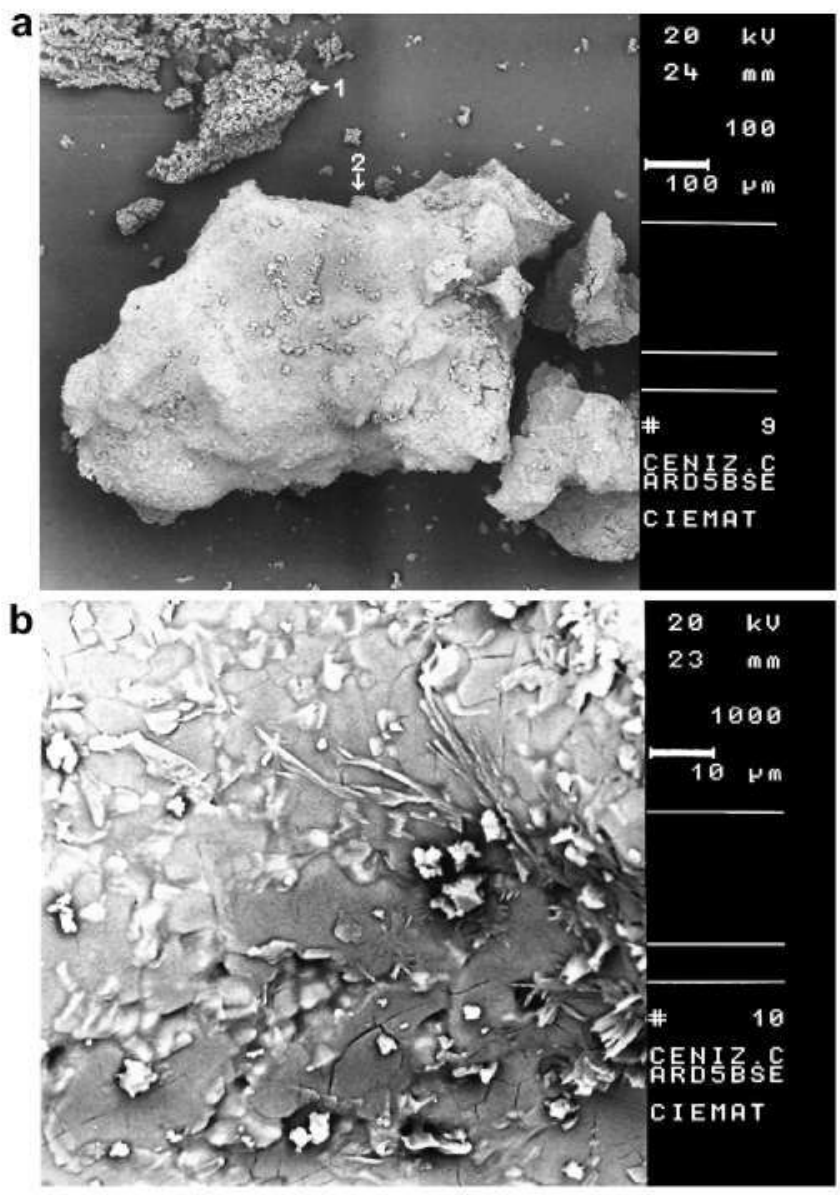

Fig. 7 - SEM-EDX photo of particles from Treatment $2 \mathrm{~K}_{2} \mathrm{SO}_{4}$ : (a) Point 1 and Point 2, and (b) detail of Point 2.

crystalline appearance observed in the SEM-EDX analysis of both type of samples. According to the results shown in the DTA curves (Figs. 4 and 6), several endothermic peaks appeared in all the fertilisation treatments. Peaks around $600^{\circ} \mathrm{C}$ were attributed to the decomposition of $\mathrm{Ca}(\mathrm{OH})_{2}$ and the endothermic peaks around $850-900^{\circ} \mathrm{C}$ proved the presence of $\mathrm{CaCO}_{3}$ and the release of $\mathrm{CO}_{2}$, although they could also be attributed to alkali release [9]. However, melting temperature eutectics were only produced at elevated temperatures when Cynara was fertilised with the highest potassium rate, with both $\mathrm{KCl}$ and $\mathrm{K}_{2} \mathrm{SO}_{4}$. This is supported by the SEM-EDX

Table 6 - SEM-EDX analysis of amorphous particles (P1) and particles with crystalline appearance (P2) found in samples corresponding to Treatment $2 \mathrm{~K}_{2} \mathrm{SO}_{4}$.

\begin{tabular}{lcc}
\hline$\%)$ & $\mathrm{P} 1$ & $\mathrm{P} 2$ \\
\hline $\mathrm{SiO}_{2}$ & 1.1 & 1.2 \\
$\mathrm{~K}_{2} \mathrm{O}$ & 3.0 & 73.8 \\
$\mathrm{CaO}$ & 92.3 & 6.9 \\
$\mathrm{MgO}$ & 2.7 & ip \\
$\mathrm{P}_{2} \mathrm{O}_{5}$ & $\mathrm{ip}$ & 13.1 \\
ip $=$ imperceptible. & &
\end{tabular}

analysis of these samples, which shows particles with crystalline appearance and high potassium content.

On the other hand, although crystalline particles were not detected in the SEM-EDX analysis, the DTA curve of the sample corresponding to Treatment $1 \mathrm{~K}_{2} \mathrm{SO}_{4}$ showed a small endothermic peak at $1086^{\circ} \mathrm{C}$.

If the potassium contents showed in Table 2 are taken into account, a relationship between the potassium content of the plant and the presence of melting temperature eutectics in the DTA curve must be considered. This appears to indicate that the appearance of these eutectics and so, possible sintering phenomena, depends on the potassium contained in the plant which in turn depends on the potassium fertilisation rate, independent of the type of fertiliser, $\mathrm{KCl}$ or $\mathrm{K}_{2} \mathrm{SO}_{4}$ (see Fig. 8). Nevertheless, besides the potassium content, as has already mentioned, the presence of other elements like silica or chlorine is also important. Thus, in the present study Treatment $2 \mathrm{KCl}$ presents the worst behaviour in the thermochemical process. This could be due to the high silicon concentration in its ash (see Table 5) and to its high chlorine content (see Table 2) since this element acts as a facilitator increasing the mobility of potassium [13]. According to these authors, potassium chloride is among the most stable high-temperature gas-phase alkali-containing species, while the amount of chlorine often dictates the amount of alkali that can be vaporized during combustion.

In the case of Treatment $2 \mathrm{~K}_{2} \mathrm{SO}_{4}$, although the SEM-EDX picture shows the presence of particles with crystalline appearance, these particles have high potassium contents but their silicon content is very low (Table 6) and the chlorine content of the biomass from that treatment was also low (Table 2). So, further studies utilizing complementary techniques such as the optical heating microscope, thermomechanical analysis (TMA) or X-ray diffraction, would be very helpful in order to corroborate the presence of crystalline particles and their fusibility temperature in those treatments which have presented endothermic peaks in their DTA curves at temperatures higher than $900^{\circ} \mathrm{C}$.

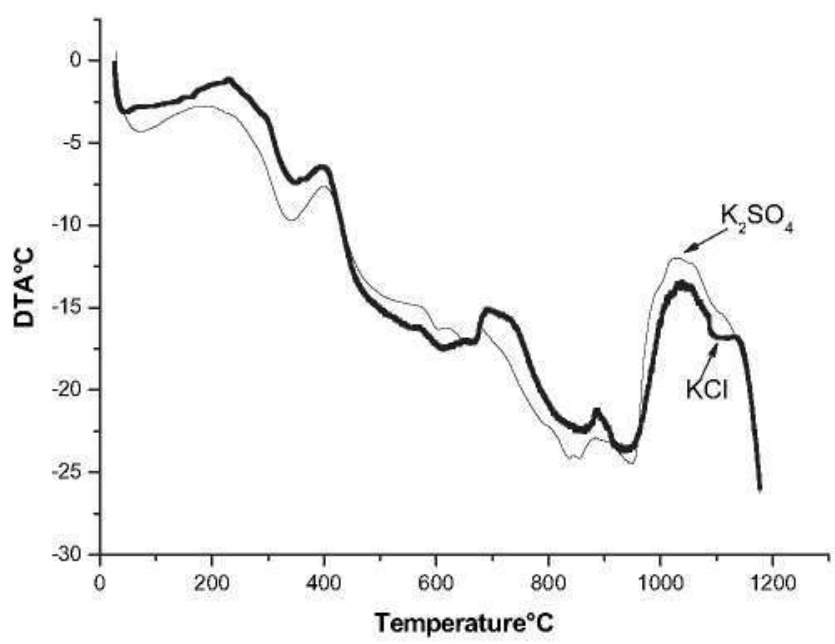

Fig. 8 - DTA curves of the samples from Treatment $2 \mathrm{KCl}$ and $2 \mathrm{~K}_{2} \mathrm{SO}_{4}$. 


\section{Conclusions}

The results of this work showed that the potassium fertilisation applied to the Cynara energy crop, and the management of the biomass at harvest, play an important role in the quality of the Cynara biomass. The potassium content of the Cynara biomass increases with $\mathrm{K}$ fertilisation. By using potassium sulphate fertilisers instead of potassium chloride fertilisers and by preventing soil contamination at harvest, biomass contents of $1.33 \% \mathrm{~K}, 0.12 \% \mathrm{~S}, 0.35 \% \mathrm{Cl}$ and $6.26 \%$ ash (wt. \% d.b.) can be achieved. According to the thermogravimetry study, sintering phenomena can be expected when a high rate of potassium fertiliser is utilized, irrespective of the type of fertiliser, $\mathrm{KCl}$ or $\mathrm{K}_{2} \mathrm{SO}_{4}$. However, the SEM images performed on samples of the four $\mathrm{K}$ treatments in this experiment did not reveal signs of ash melting, although some particles with a crystalline appearance appeared in the samples from highly $\mathrm{K}$-fertilised treatments.

On the other hand, taking into account that the melting temperature eutectics observed in the DTA curves occur at temperatures higher than $1000^{\circ} \mathrm{C}$, Cynara could be utilized in thermochemical processes that do not reach such high temperatures, like for example fluidized bed combustion.

\section{Ackmowledgements}

This work was financed by the Spanish 'Ministerio de Educacion y Ciencia' (Ministry of Education and Science) as project BIOCOMCARD ENE2004-07624-C03-01. The authors thank Dr. Cozar for the SEM-RDX analysis and Mr. Champion for the English editing of the manuscript.

\section{R E F E R E N C E S}

[1] Fernández J, Curt MD. State-of-the art on Cynara cardunculus as an energy crop. In: Sjunnesson L, Carrasco JE, Helm P, Grassi A, editors. Biomass for energy, industry and climate protection, Proceedings of the 14th European Biomass Conference, Paris 17-21 October 2005. ETA-Renewable Energies \& WIP-Renewable Energies, ISBN 88-89407-07-7; 2005. p. 22-5.

[2] Abrantes S, Amaral ME, Costa AP, Duarte AP. Cynara cardunculus L. alkaline pulps: alternatives fibres for paper and paperboard production. Bioresource Technology 2007;98: $2873-8$.

[3] Fernández J, Curt MD, Aguado PL. Industrial applications of Cynara cardunculus L. for energy and other uses. Industrial Crops and Products 2006;24:222-9.

[4] Aho M, Gil A, Taipale R, Vainikka P, Vesala H. A pilot-scale fireside deposit study of co-firing Cynara with two coals in a fluidised bed. Fuel 2008;87:58-60.

[5] Coulson M, Dahl J, Gansekoele E, Bridgwater AV, Obernberger I, Van de Beld L. Ash characteristics of perennial energy crops and their influence on thermal processing. In: Van Swaaij WPM, Fjällström T, Helm P, Grass
A, editors. Proceedings of the 2nd World Biomass Conference; 2004. p. 359-62.

[6] Benlloch-González M, Foumier JM, Ramos J, Benlloch M. Strategies underlying salt tolerance in halophytes are present in Cynara cardunculus. Plant Science 2005;168:653-9.

[7] Obernberger I, Bidermann F, Widmann W, Riedl R. Concentrations of inorganic elements in biomass fuels and recovery in the different ash fractions. Biomass and Bioenergy 1997;12:211-24.

[8] Van Loo S, Koppejan J, editors. The handbook of biomass combustion and co-firing. London: Earthscan; 2008. p. 47.

[9] Davidsson KO, Korsgren JG, Pettersson JBC, Jäglid U. The effects of fuel washing techniques on alkali release from biomass. Fuel 2002;81:137-42.

[10] Steenari $B-M$, Lindqvist $O$. High temperature reactions of straw ash and the anti-sintering additives kaolin and dolomite. Biomass and Bioenergy 1998;14(1):67-76.

[11] Zevenhoven-Onderwater M, Blomquist JP, Skrifvars BJ, Backmam R, Hupa M. The prediction of behaviour of ashes from five different solid fuels in fluidised bed combustion. Fuel 2000;79:1353-61.

[12] Gasol CM, Gabarrell X, Anton A, Rigola M, Carrasco J, Ciria P, et al. Life cycle assessment of a Brassica carinata bioenergy cropping system in southern Europe. Biomass and Bioenergy 2007;31:543-55.

[13] Miles TR, Miles Jr TR, Baxter LL, Bryers RW, Jenkins BM, Oden LL. Boiler deposits from firing biomass fuels. Biomass and Bioenergy 1996;10(2-3):125-38.

[14] Davidsson KO, Pettersson JBC, Nilsson R. Fertiliser influence on alkali release during straw pyrolysis. Fuel 2002;81:259-62.

[15] Fernandez J, Curt MD, Luque S, Sánchez G, López C, Hidalgo M. Multilocal study of the contents in N, P \& K of Cynara cardunculus L. biomass. In: Palz W, Spitzer J, Maniatis K, Kwant K, Helm P, Grassi A, editors. Proceedings of the 12th European Conference on Biomass for Energy, Industry and Climate Protection, vol. I. ETA-Florence \& WIP-Munich, 1SEN 3-936338-10-8; 2002. p. 198-201.

[16] Dahl J, Obernberger l. Evaluation of the combustion characteristics of four perennial energy crops (Arundo donax, Cynara cardunculus, Miscanthus $x$ giganteus and Panicum virgatum. In: Van Swaaij WPM, Fjallstrom T, Helm P, Grassi A, editors. Proceedings of the Second World Biomass Conference, Biomass for Energy, Industry and Climate Protection, 10-14 May, vol. II. Rome, Italy: ETA-Florence and WlP-Munich; 2004. p. 1265-70.

[17) Phyllis, database for biomass and waste. Energy Research Center of the Netherlands. Available at: $<$ http://www.ecn.nl/ Phyllis/> [accessed 6.04.10].

[18] Jørgensen JR, Deleuran LC, Wollenweber B. Prospects of whole grain crops of wheat, rye and triticale under different fertilizer regimes for energy production. Biomass and Bioenergy 2007;31:308-17.

[19] Xie W, Xie Y, Pan W-P, Riga A. Characterization of the ash deposits from AFBC system using thermal techniques. Thermochimica Acta 2000;357-358:231-8.

[20] Erdey L, Liptay G, Svehla G, Paulik F. Indirect derivatographic determination of calcium, strontium and barium ions in the presence of one another. Talanta 1962;9(6):489-93.

[21] Olanders B, Steenari B-M. Characterization of ashes from wood and straw. Biomass and Bioenergy 1995;8(2):105-15.

[22] Arvelakis S, Gehrmann H, Beckmann M, Koukios EG. Preliminary results on the ash behaviour of peach stones during fluidized bed gasification: evaluation of fractionation and leaching as pre-treatments. Biomass and Bioenergy $2005 ; 28: 331-8$. 